\title{
Defining Health Service Eco-System “Infection”: A Critical Analysis of Patient Surveys
}

\author{
Maria V. Ciasullo ${ }^{1}$, Orlando Troisi ${ }^{1}$, Silvia Cosimato ${ }^{1} \&$ Alex Douglas $^{2}$ \\ ${ }^{1}$ Department of Management \& Innovation Systems, University of Salerno, Italy \\ ${ }^{2}$ Management University of Africa, Nairobi, Kenya \\ Correspondence: Maria V. Ciasullo, Department of Management \& Innovation Systems, University of Salerno, \\ Italy. E-mail: mciasullo@unisa.it
}

Received: June 12, 2018

doi:10.5539/ijbm.v13n9p118
Accepted: July 20, $2018 \quad$ Online Published: August 1, 2018

URL: https://doi.org/10.5539/ijbm.v13n9p118

\begin{abstract}
Purpose - This paper focuses on the analysis of the most common tools that health care organizations use to assess the quality of the delivered services, the patient surveys. In line with the results of a systematic literature review on the issue, the study embraces service ecosystem perspective to understand why these surveys are unable to grasp actors' disposition to co-create value for the health care system.
\end{abstract}

Methodology - An in-depth literature review based on PRISMA framework explored 34 works on the topic of patient surveys in order to trace the evolution of the relationship users/providers and to highlight the criticalities related to the adoption of patient surveys in service-oriented era. The study discusses critically their efficacy to understand how they can affect (positively or negatively) the viability of a health care service eco-system.

Findings - The literature review highlights patient surveys inability in grasping the real perception that patients have of experienced services and in involving them in value co-creation, through their engagement in service design and delivery. Moreover, the results reveal the need to adopt Service Dominant (S-D) Logic and service eco-system perspective to reread the traditional tools to measure quality in healthcare. For this reason, the metaphor of health service eco-system "infection" is launched, depicting the negative influence of patient satisfaction surveys on value co-creation and the subsequent service eco-system viability.

Practical implications - The study shows that assuming a service eco-system perspective based on S-D logic, health care system should boost and preserve value co-creation processes. Moreover, institutions should foster those "rules of the game" that institutionalize the contribution of health providers to value co-creation, defining specific strategies to avoid the "infections" of health care service eco-system, e.g. investing and promoting non-detrimental tools.

Originality - This study represents one of the first attempts to reread the tools used to assess patient embracing a service eco-system perspective. Interesting implications have been presented in terms of the negative effect that traditional assessment tools have on providers, patients and the whole society.

Keywords: S-D Logic, health care service ecosystem, patient surveys, infection

\section{Introduction}

Health care is one of the most complex and challenging issue, we face; thus, it pervades almost all societal dimensions, influencing highly both economies and individuals' quality of life (Berry \& Bendaputi, 2007).

Currently, health care service domain is characterized by several tricky problems. Thus, institutions have to find new ways to solve, among others, the rise in costs - improving, simultaneously, the quality of the provided services (Carter \& Silverman, 2016), - the number of medical errors, the high tendency towards the discrimination and the rising demand for high quality services (Polese \& Capunzo, 2013).

To face those afore-mentioned as well as the other problems that still affect the National Health Care Systems (NHCS) of developed countries, some systemic interventions are needed to boost the health state of each individual, the quality of their and their families daily life as well as the wellbeing of the whole society. However, the literature underlines that an outdated managerial logic still characterize health care organizations, which lead them to consider health quality as strictly dependent on the use of sophisticate medical treatments and tools as well 
as on innovative delivery systems (Heidegger, Saal, \& Nübling, 2013). To date, none of these interventions completely fits what people inherently desire and ask for, that are the resolution to their health problems and the achievement of a global sense of wellbeing (Joiner \& Lusch, 2016). This situation is mainly due to -health organizations enduring focus on "products" (e.g. hospitalization, ambulatory care, medications, procedures, therapeutic care, etc.) and their failure to embrace a service-centered view (Chakraborty, Bhattacharya, \& Dobrzykowski, 2014).

Thus, the persistence of product-oriented view let extant research to redefine the role of service beneficiaries considered not as patients, but as real customers - and to define and assess the nature of the value that they should contribute to co-create (Vargo \& Lusch, 2008; McColl-Kennedy, Vargo, Dagger, Sweeney \& Kasteren, 2012). In so doing, health institutions and consequently health organizations should focus on those health service's attributes that patients, in their role of customers, and, consequently, society judge as most valuable, in order to emphasize and better develop them.

With the aim to boost health services, service providers have increasingly implemented customer oriented assessment systems, so, as the literature confirms, the most common of them have been operationalized as patient surveys (Dufrene, 2000; Heidegger, Saal, \& Nuebling, 2006; Gill \& White, 2009). In health service domain, these tools are commonly considered as pointing to assess specific components of health service quality and as a primary source of information about patients' perception. Service providers usually apply these surveys in a no proactive way; consequently, they tend to fail in grasping the real perception that patients have of health service quality (Gill, White, \& Cameron, 2011). Moreover, being these tools just used during the discharge moment, patients' responses tend to be highly influenced by their illness state, which led them to be essentially ill-considered, whimsical, or affected by unstable thoughts and feelings (Fitzpatrick, 1991). It follows that the most of tools for assessing health quality fails to understand what value really means for both patients and service providers, being the quality, performance and outcomes of a service process shaped primarily by users' expectations, their active or passive role in service delivery process and their subsequent experience of that process.

The quality of health services has to be approached as linked to value, which health as well as any other institutions strive to create and provide and which cannot be relegated - as patients' surveys do - to simple patients' judgments (Sitzia \& Wood, 1997). To counteract this situation, health service providers are called to consider that health service delivery involves many actors, including patients and those belonging to their personal network who highly affect the quality of the service. This implies that health organizations should embrace a patient-centered approach to care (Rathert, Wyrwich, \& Boren, 2013) in order to develop patient-related measures, built upon patients' and their network direct contribution. This makes patient-related measures able to grasp their real needs and wants on which service should be redesigned in order to be as complying as possible with their demands. It follows that all the actors - directly and indirectly involved in patients' health process - are, at the same time, source of and contributors to service quality (Ciasullo, Cosimato, \& Douglas, 2017).

The latest trends of service research address the new active role of users and the renewed concept of quality adopting the Service-Dominant Logic (Vargo \& Lusch, 2004) and shedding lights on customers' centrality in service co-production, who act as resource integrators and value co-creators (Chandler \& Vargo 2011; McColl-Kennedy et al. 2012; Vargo \& Lusch, 2017). These arguments let to better understand the importance of patients' active engagement in the co-production of health service and, consequently, in the co-creation of value for themselves, other actors and the whole health service ecosystem (Vargo \& Lusch, 2016). In fact, S-D Logic and service ecosystem perspective highlight the importance of both service providers and patients' empowerment, which roots on their ability - being sensing and experienced - in using their personal skills and knowledge to benefit each other (Joiner \& Lusch, 2016). Service ecosystem perspective represents the most suitable metaphor to investigate the way patient surveys, spreading from the micro-level dyads (e.g. patient-service providers), enhance or constrain value co-creation at all ecosystem levels.

Drawing on the shifting from a product-oriented to a service-oriented logic proposed by the extant research in healthcare systems, this work aims at reviewing the literature on the topic to verify the evolution of the role of patients and, subsequently, of the instruments to assess their quality and expectations. Therefore, the paper aims to answer the following questions:

RQ1: Which is the state of the art on patient's role and of their relationships with providers? Are patient surveys customer oriented or not?

RQ2: How can patient surveys be reread according to the new S-D logic? Why can they "infect" health service eco-system?

The first research question is addressed through the literature systematically reviewed, while the second rereading 
patient surveys according to the service ecosystems view. Finally, the study discusses the effect that patient surveys can have on value co-creation process and their influence - positive or negative - on the wellbeing of health service ecosystem.

The remainder of the paper is organized as follows. In the next section the methodology is presented, follows a systematic literature review covering the issues addressed in the paper, patient's perceived quality and patient surveys. Drawing on the results of the reviewed literature, which pointed out the need for analyzing patient perceived quality according to a broader perspective, the following section critically discuss the role and the effectiveness of patient surveys. The last section reads patient surveys according to S-D logic principles and the service ecosystem perspective. Finally, theoretical and managerial implications are discussed, paving the way for further research.

\section{Methodology}

\subsection{Research Approach}

Following the two research questions outlined in the previous section, a systematic literature review (SLR) based on an inductive content analysis has been performed to identify how patient's perceived quality is understood in current management literature, and assess if the traditional tools for measuring quality meet the current vision of service (are service-oriented). Therefore, the review of literature aims to define the evolution of patient's quality conceptualization in managerial literature (theoretical viewpoint) and if the traditional patient surveys are complying with the current view on patients perceived quality (empirical viewpoint). To reach these aims, between January and April 2018 three researchers on services management carried out a systematic literature review according to the PRISMA (Preferred Reporting Items for Systematic Reviews and Meta-Analysis) methodology (Moher, Liberati, Tezlaff, \& Altman, 2009). Thus, a systematic review of the literature let to prevent the most common bias of a narrative literature review, offering, thanks to a four-steps and a well-defined process, better methodological accuracy (Tranfield, Denyer, \& Smart, 2003), replicability and transparency. Moreover, this approach let also an in-depth investigation of a massive amount of contributions and, in so doing, boost the detection/finding of unexplored issues (Mulrow, 1994).

\subsection{Describing the Review Process}

\subsubsection{Data Collection}

Three databases have been created to ensure an appropriate coverage of the issue and to include a broad range of outputs: Scopus, Emerald and Web of Science. These search engines have been chosen due to their comprehensiveness and their relevance in social sciences. The selected keywords, which aim at covering semantically and adequately the topic, have been connected with the "AND" and "OR" Boolean operators. Thus, the following search string has been defined: patient survey "OR" patient surveys "AND" healthcare service quality "AND" patient satisfaction.

\subsubsection{Data Extraction Procedure and Inclusion Criteria}

The four phases performed according to the PRISMA framework (see Fig. 1) are: 1) identification, 2) screening, 3) eligibility, and 4) inclusion. After having matched the results obtained from the three databases during the identification phase (6800 from Web of Science, 2403 from Emerald, 991 from Scopus=10.196), duplicates (349) were removed and 674 studies were screened around according to their titles and abstracts in order to exclude the less relevant contributions (screening phase).

Drawing on the two research questions, some sub-topics were defined to quickly analyse the abstracts and to ensure the relevance criterion (patient's role, patient's engagement, patient satisfaction, patient perceived service quality, healthcare service quality, healthcare service quality measurement, etc.). Then, according to the reading of abstract, 487 papers were eliminated, because of their low pertinence to research aims, while 187 full papers were red (eligibility phase). Finally, according to the application of eligibility criteria, a final set of 34 works (inclusion phase) was analysed through the transformation of sub-topics into categories for coding. In line with Cooper's methodology $(1998 ; 2010)$, the final criteria used to select the eligible studies were:

1) the use of English language;

2) the publication on peer-reviewed journals;

3) the pertinence of the research area (management, economics, service science and social sciences), due to the database categorization;

4) the number of citations; 
5) the congruity with the two main research aims: a) the theoretical one, works with a clear standpoint on patient quality and on patient's role, and b) the empirical one, works that investigate the tools used to measure patients' perceived quality or satisfaction.

The application of these filters let to detect and select for an in-depth content analysis, performed through coding, just the papers drawing on patients' perceived quality from both a theoretical (goal 1) and an empirical viewpoint (goal 2).

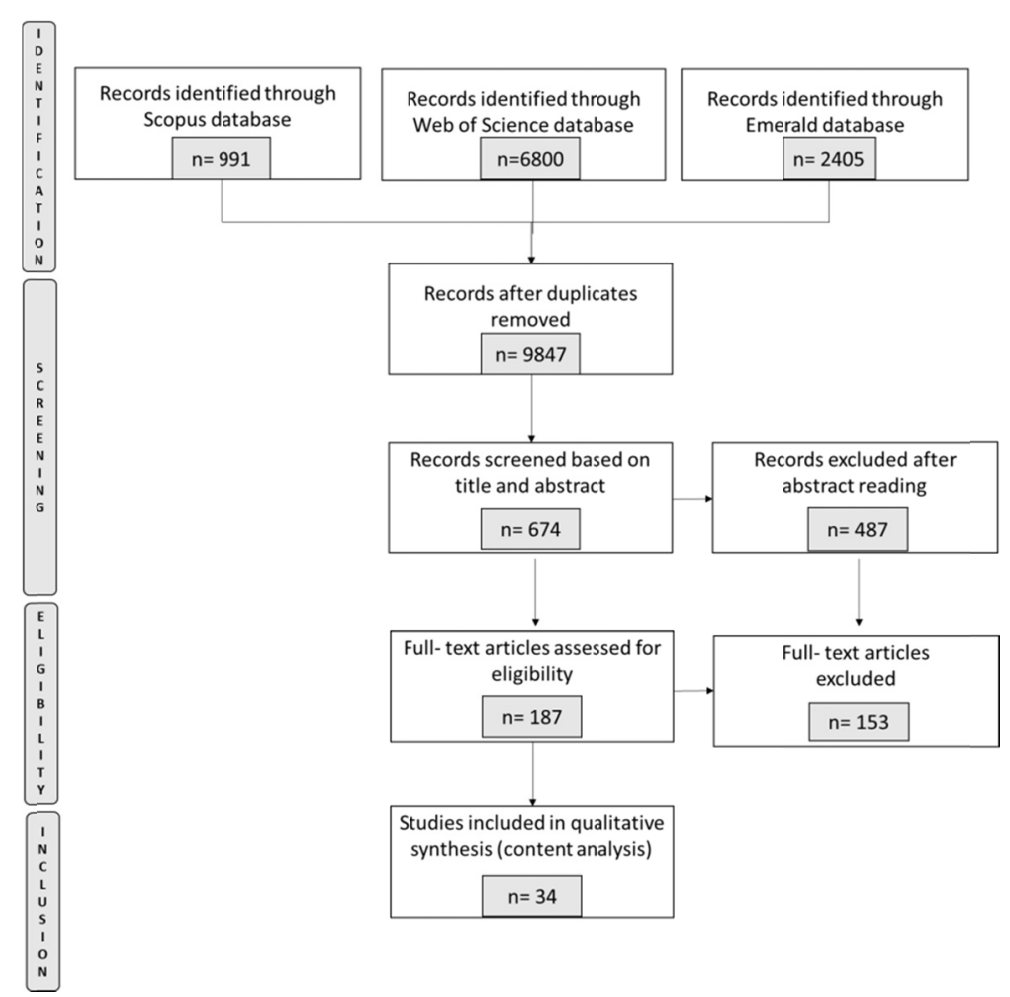

Figure 1. PRISMA flow diagram: research design

source: our elaboration

In the following, an inductive methodology, based on the content analysis (Kassarjian, 1977; Graneheim \& Lundman, 2004; Krippendorff \& Bock, 2009), was applied to the final set of works resulting from the SLR. No a priori classification criteria were used to analyse the selected papers, while in the sampling phase specific keywords were used to simplify the screening of the several contributions resulting from the initial research stages.

Focusing on the content analysis it seems to be a suitable technique for investigating complex and immaterial concepts (such as quality, perceived quality or engagement) related to psychological, sociological and context-dependant elements. Based on researchers' subjective interpretation, this technique, adopting a critical attitude, supports a conceptual and semantic investigation of those constructs not well defined in literature.

The works have been coded independently from the three researchers; thus, during the process, the labels, identified before the coding, were revised and, after the matching of the analyses of the three researchers, were combined in order to derive the four macro-areas presented in figure 2.

The critical analysis, based on the interpretation of the four macro-areas, let to propose the application of the ecosystem view to the traditional view on patient quality and patient surveys (See paragraph 5).

\section{Findings: A State of the Art of Patient Surveys in Healthcare Service}

With the advent of patient rights movement (Williams, 1994), the standard of technical care shifted towards the process of care assessed by the patient. As a result, in the health care the use of patient surveys, intended to evaluate and improve the quality of the provided services, became increasingly widespread (Quintana, Escobar, Arostegui, Bilbao, Azkarate, Goenaga, \& Arenaza, 2006). 
Based on the two research questions that inspired this analysis, the review of literature aim at understanding the conceptualization of patient's perceived quality, according to the evolution of patient's role and of patients-providers relationship and at investigating the different approaches to the measurement of patients' perceived quality based on patient surveys.

The coding procedure described above let to point out four main approaches existing in the extant research: 1) Outcome-based approach; 2) patients' empowerment; 3) patients experience; 4) service ecosystems view. The classification has been obtained from the intersection of two variables, as figure 2 shows: 1) dyadic/systems conception of healthcare services; 2) measurement of functional quality/satisfaction vs inclusion of immaterial and intangible features involved in quality.

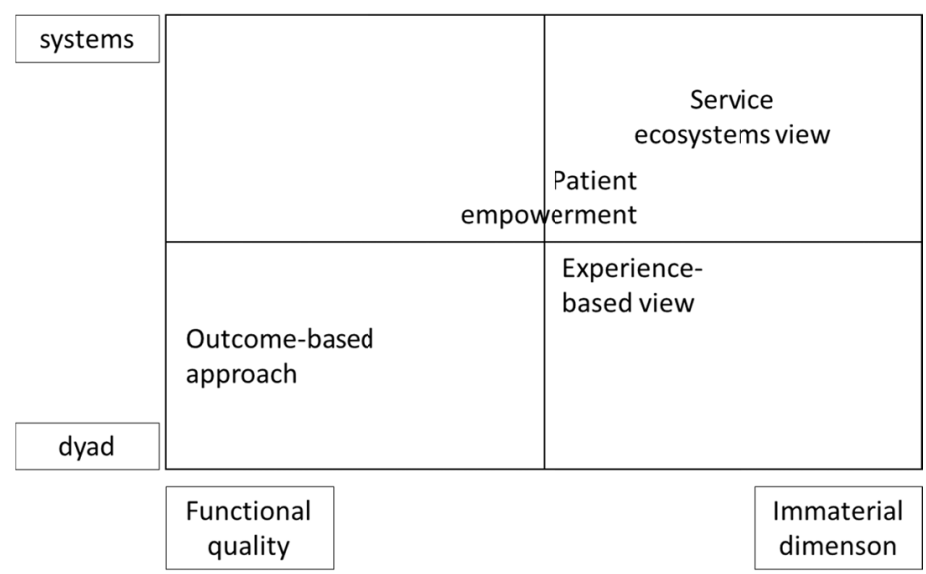

Figure 2. Classification into for main macro-areas or approaches to the analyzed contributions

Source: our elaboration.

The first research stream (outcome-based approach) focuses on the evaluation of the effectiveness of the use of patient-based measures in health routine practices in improving the process and outcomes of patient care. In this framework, the relationship between users and providers is conceived as unidirectional and is characterized by informational asymmetry.

This perspective gives birth from classical studies on health care context, in which value has been described traditionally as related to the outcomes/cost (Porter, 2010). In fact, if costs have an obvious estimation and formulation, outcomes have a more difficult conceptualization and several measures have been defined to indirectly assess them through common metrics such as mortality, life expectancy and infection rates. Analyzed within the dyad service providers-patients, the quality of care is intended as a fundamental outcome of patient satisfaction (Heidegger et al., 2006).

The studies included in this perspective focus mainly on the impact of patient surveys on: 1) improvement of performances and outcome; 2) patient individual satisfaction (Wasson et al., 1992) Wagner, Ehrenberg, Tran, Bungay, Cynn \& Rogers, 1997; 3) user's positive attitude (Moore, Siu, Partridge, Hays \& Adams, 1997; Kazis, Callahan, Meenan \& Pincus., 1990) mental health and psychology (Mazonson, Mathias, Fifer, Beusching, \& Malek., 1996 Dowrick, 1995).

Therefore, a behaviorist approach grounded on the research of the relationship stimulus response and on the passive role of patients. Patient satisfaction is still measured as a proxy for making patients capable at assessing the quality of services (Turris, 2005).

The second approach (experience-based approach) identified stems from the willingness to overcome outcome-based view. In fact, because of its peculiar traits, health care quality arises gradually as a quite knotty problem (Eiriz \& Figueiredu, 2005; Pay \& Chary, 2013) that delves on those patients' psychophysical and emotional needs which affect their quality of life.

For this reason, the experience-based view has been proposed to measure the value experienced by patients. Functional value (the most fitting treatments with patients' needs), emotional value (related to several positive or negative emotional states due to service consumption), and cognitive value (the subjectivity of views, mental 
framework, perspectives and expectations) define the essential quality outcome according to patients' perception and under which they perform a given behavior (Edvardsson et al., 2011). It follows that patients' experience is one of the most critical health outcome, which represents the most effective source of knowledge to assess the perception of service quality and to support health service providers in understanding service quality standards (LaVela \& Gallan, 2014).

Even if patient satisfaction is considered a part of health outcome quality, which also includes clinical results, economic measures and health related quality of life (Heidegger et al., 2006), this research stream conceives service quality as the exclusive antecedent to satisfaction with health services (Dagger, Sweeney, \& Johnson, 2007). Moreover, it focuses only on the bidirectional (but dyadic) relationship users-providers without broadening the view to other members involved in healthcare system.

Starting from the need to extend the actors included actively in the provision of healthcare services (Swan, 2009), the third framework identified (patient empowerment) defines health care as a complex, dynamic and adaptive service system in which individuals are the most critical component and in which services are highly skilled and knowledge-intensive (Berry \& Bendapudi, 2007).

The research stream aims at overcoming the traditional conception of proxy measures that are used typically to assess patients' satisfaction without including their overall well-being. For example, using the blood pressure as a measure of satisfaction, getting a pressure rate within a defined range not always corresponds to patient's view of the optimum wellbeing. In fact, when patients are treated with a specific medication to reduce blood pressure, it should be considered that possible side effects might affect the global quality of their life. Therefore, health providers should ask themselves if these results make possible to state that the ultimate goal (patient well-being) is achieved. Going further, even when the service is provided through high quality facilities some specific and non-removable traits (e.g. use or movement of medical equipment, nursing shift changes, alarms, etc.) can negatively affect the experience that patients live during their hospitalization, causing stress and psychological sufferings that constrain their overall well-being (Berry, Carbone, \& Haeckel, 2002).

In sum, the above-mentioned examples imply the need for service provider to embrace a patient-centered approach, according to which patients are not passive receivers of medical information and services, but active contributors of health service (Rather et al., 2013). In this vein, the involvement of patients in service is fundamental to enhance both health outcomes and patients' satisfaction. More in details, patients can play different roles, acting as both a productive resource and a contributor to quality, satisfaction and value of medical services. To this end, they should be engaged in different activities, even if the engagement calls for a greater effort of service providers that goes beyond patients' traditional contribution to their own care (Badcott, 2005).

The current service literature on patient empowerment and engagement highlights that when patients are actively involved in health processes (Bendapudi \& Leone, 2003) they are more likely to follow providers' advices (Dellande, Gilly, \& Graham, 2004; Godolphin, 2009) in a shared decision-making. When takes the form of shared decision-making, patients participation can also improve psychological well-being, medical status and the satisfaction with their physicians (Fallowfield, Hall, Maguire, \& Baum, 1990); however, not all patients and service providers demonstrate a similar disposition (Lòpez-Jornet \& Camacho-Alfonso, 2010).

Health research on this topic underlines that patients' awareness about their contribution in service exchange is fundamental to achieve the desired outcomes (Zainuddin, Previte, \& Russell-Bennett., 2011) and to affect the ultimate and perceived service quality (Gilly, White and Cameron, 2011; Tommasetti, Troisi, \& Cosimato, 2014). Consequently, health professionals should boost the flexibility and the personalization of care provision, nourishing those service interactions based on patients' needs, expectation and real-life experiences (Vredenburg $\&$ Bell, 2014).

The last perspective derived from literature review stems mainly from service ecosystem view, promoted by Vargo \& Lusch (2011) and from S-D logic research in general. In this research stream, the notion of patient's quality and satisfaction is associated with - and in some cases included in- the key concept of value co-creation, which is the ideal outcome of healthcare system intended as a set of service systems encapsulated in each other's.

One of the first contributions that introduces systems view on healthcare is from Wickramasinghe, Chalasani, Boppana, and Madni (2007) that understood health care as a system of systems or a set of self-regulating, extensive, intricate and distributed systems.

In this vein, service eco-systems and a system-level thinking (Lusch \& Spohrer, 2012) should led to better understand the complexity at the core of health care service. This let to embrace a holistic approach to healthcare, according to which it can be depicted as a set of multiple actors, which interactions shifted from dyadic to triadic 
and even to a complex network, made up of direct and indirect service-for-service exchanges (Ciasullo, Cosimato, \& Palumbo, 2017; Palumbo, Cosimato \& Tommasetti, 2017; Barile, Saviano, \& Polese, 2014). Therefore, it is possible to infer that health care perfectly fits with the service ecosystem structure. In fact, the human entities who populate it (e.g. patients, families, physicians, nurses, hospitals, clinics, nursing homes, pharmacies, government regulatory groups, licensing and funding agencies, insurance companies, etc.) co-exist with a number of non-human entities (e.g. public and private economic resources, laws and regulations, cultures, hospital/clinic management style, country reputation, hospital/clinic reputation, technology, etc.) which shape the way they act together. Moving under a growing uncertainty, actors have to adapt, learn and adjust the way they act and interact. The co-existence of human and non-human entities as well as the interplayed interactions occurring among actors led to define it as a complex ecosystem.

With reference to relationship between quality and value co-creation, according to Nambisan \&Nambisan (2009), value co-creation enhances knowledge exchange and in turn increases perceived service quality. Moreover, the concept of patient quality is broadened to include well-being and quality of life. According to McColl-Kennedy et al. (2012) and Frow et al. (2016), value propositions have a key role in strengthening the relationships between different actors in the ecosystem (from customers to suppliers to institutions, etc.) and may increase the importance of relationships with friends and family. The overall result of value co-creation includes an increasing in the quality of life and some relevant changes in user's habits, behavior and practices (Tommasetti, Troisi, \& Vesci, 2017).

Since users perform the role of active co-creator, service providers' technical competences such as professional skills, expertise and knowledge should be complemented by patients' skills and knowledge in an ongoing process of mutual adjustment. Therefore, medical and non-medical staff turn into value proposing actors (Vargo \& Lusch, 2011); however, users' active participation due to the involvement and the engagement of patients in resource sharing activities led to meet their needs and to shape the expectations of value-in-use. It follows that patient value, operationalized in terms of well-being, is necessarily co-created and nourished by dynamic and multiple service interactions.

This led to approach health service quality and patient satisfaction as rising from the ability not only in delivering cares even more fitting with peculiar diseases (e.g. the application of a care protocoll, a technically reliable computed tomography, etc.), but rather in considering patients' operant resources (or providers of ideas, knowledge, social skills, attitude towards medical services, etc.) mutually integrated in health service provision. Therefore, the perceived quality of service rises from those valuable and shared interactions occurring between service providers and patients, also supported by the active involvement of other individuals (Holman \& Lorig, 2000). Thus, health providers should grasp the changing trends of patients' behavior and should include patients' expectations and goals into their practices to gain positive health outcomes and patient satisfaction.

The different conceptualizations of patient's role, quality and patient surveys identified in the four research streams are synthesized in table 1.

Table 1. Critical synthesis of the final set of contributions: a classification into four approaches

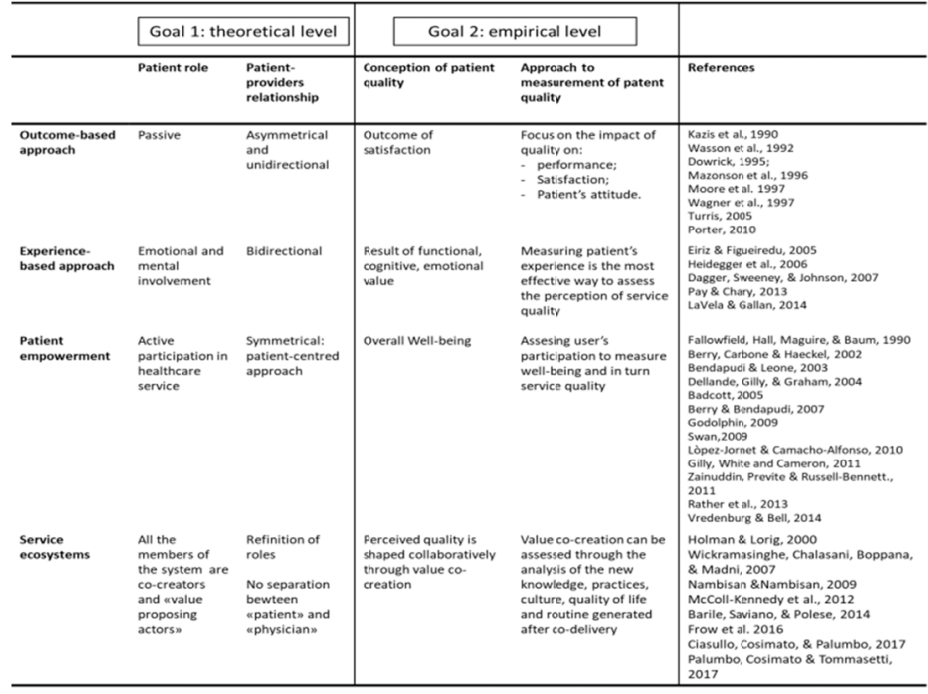




\section{Results: A Critical Reading of Patient Surveys}

The main finding of the literature review is the persistence of a misconception of patient satisfaction and perceived quality (Gill \& White, 2009) that for a long time have been misinterpreted or understood according to a narrow approach that interpreted quality in terms of "simple" satisfaction. Over the course of time, thanks to the introduction of patient empowerment and S-D logic, the concept of patient quality has been extended to include well-being and to stress that final service quality is not determined univocally by providers but is co-created with patients and other members of healthcare ecosystem.

However, despite the adoption of patient-centered views (patient engagement and S-D logic), patient surveys present some significant flaws that can determine a wicked or inappropriate use of resources as well as actors' improper attitude or roles can constrain the viability and therefore the sustainability of the whole eco-system

Even if from a theoretical point of view a shift toward a system conception of quality has occurred, regarding the real measurement of patient quality still lays the core dyad patients-health service providers (e.g. physicians, general practitioners, nurses, nonmedical staff such as receptionists, administrative personnel, etc.). Therefore, the effects of these dyadic service interactions can affect positively or negatively the other ecosystem levels in terms of value co-creation or value co-destruction (Plè \& Chumpitaz Càceres, 2010).

In this vein, contemporary patient surveys used to assess the quality of the delivered service sounds unable in grasping the inner complexity of this service. In detail, the main limitations identified through the systematic literature review- that will be discussed below, are:

1. focus on process that contributes to underrate individual differences;

2. high standardization of surveys (questions and responses options);

3. "power" of influence of providers on user's evaluation;

4. limited time of assessment (discharge);

5. focus on objective and functional quality, composed of physical ambient, infrastructure, facilities, accessibility, cleanliness (healthscape);

6. lack of analysis of psychologic and emotional features;

7. missed investigation of personal traits of different subjects;

8. administration of survey exclusively to patients not involving the other members in their networks (family, friends, etc.).

Even if surveys have been largely conceptualized in literature and applied in empirical research (Gonzales, Padín-López \& de Ramón-Garrido, 2005), they offer superficial and often overgeneralized results (Quintana et al., 2006). More in details, the assessment of service quality deeply changes according to the meaning attached to the concept of patient satisfaction (Gilbert, Veloutsou, Goode, \& Moutinho, 2004). Thus, patient surveys are characterized by a number of measures (Kleefstra, Kool, Veldkamp, Winters-van der Meer, Mens, Blijham \& de Haes, 2010), developed just to "detect what it is designed to detect" (Heidegger et al., 2013, p. 1168) and lacking in evidence about their psychometric properties (Hawthorne, Sansoni, Hayes, Marosszeky, \& Sansoni, 2006).

Some studies (Perneger, 2004; Hekkert, Cihangir, Kleefstra, van den Berg, \& Kool, 2009) considered the lack of consensus and the use of several different approaches to assess patient satisfaction (e.g. expectancy-disconfirmation, performance only, technical-functional split, satisfaction versus service quality, attribute importance, etc.) (Gilbert \& Veloutsou, 2006), as some of the main weaknesses of these surveys. In fact, it worth noting that a number of limits affect these surveys, which open doubts about their reliability. The most general of them concerns their focus on the nature of processes, rather than on individuals, being designed to detect the elements that can improve service quality and efficiency (Carman, Maurer, Yegian, Dardess, McGee, Evers, \& Marlo, 2010). More in details, even though patient surveys focus on the nature of processes, they are characterized also by low discriminative abilities (Jenkinson, Coulter, Bruster, Richards, \& Chandola, 2002). This makes them unable to grasp and depict the differences existing, for example, between a hospital and its departments. More in details, they usually achieve an omni-comprehensive result, often related to the overall satisfaction with a specific process and not referred to the way providers perform it as well as patients perceive it during their staying in a department (e.g. hospital cleanliness, staff courtesy, physicians' empathy, rooms comfort, etc.).

The above-mentioned limitation is due to the high standardization, which makes these surveys focused to the assessment of the objective quality of services intended as the evaluation of things or events made through predetermined, measurable and verifiable standards (Zeithaml, 1988). Conversely, standardization makes these 
tools not able to catch those personal shades at the core of patients' perceived quality as well as their psychological and motivational disposition towards health services (Ransom, Jacobsen, Schmidt, \& Andrykowski, 2005). More in details, they fail to involve the different and multifaceted patients' categories, constraining the participation of individuals with particular socio-economic state, for example those individuals who are socially marginalized, because suffering from severe ills or because heard to reach (Draper, Cohen, \& Buchan, 2001). Moreover, the standardization of patient surveys does not consider the aspects related to different diseases or treatments experienced by patients. In fact, disable, chronic or terminal patients should not be approached the same way, because - due to their physical, psychological, emotional and health traits - they have specific needs and a different perception of the experienced service.

Another limitation due to surveys' standardization is that they are built upon fixed-choice answers (Zaller \& Feldman, 1992), among which patients have to choose the alternatives most fitting with their experience. This implies that medical providers, defining a priori the alternative responses, can address the respondents towards a specific issue before submitting the questionnaire, limiting patients' ability in reporting what their really think about the experienced service. This characteristic might be ambiguous and not appealing for patients (Pascoe, 1983; McKinley, Manku-Scott, Hastings, French, \& Baker, 1997), discouraging them from responding, because none of the fixed-choice answers fit with their opinion, because of the inability to completely understand questions, the poor education or the lack of interest (McColl-Kennedy et al., 2012). This also implies that surveys tend to hide patients' dissatisfaction with the experienced service (Locker \& Dunt, 1978), simplifying their point of view and overestimating their satisfaction.

The influence that providers can play upon patient surveys concerns also the actions they might do to gain higher ratings (Jenkinson et al., 2002). For example, medical and non-medical staff can exploit them to influence patients' ratings changing their manners and behavior. This implies staff ability in assuming a friendly and informal behavior, in offering facilities or in having a personal relationship with patients. Thus, due to the fact that the delivery of a medical service starts when a patient books an appointment with a doctor, a receptionist can decide to push patient ahead of the waiting list to gain positive scores during the assessment of satisfaction with service.

Patient surveys are also limited by the timing of assessment, intended as the phase in which surveys are administered and which usually corresponds with patients' discharge or with the moment just following doctor's consultation. Asking patients about their satisfaction with health care service at the end of service delivering does not capture the influence of several happenings and the related feelings (e.g. experience related to previous treatments, feelings before a treatment, physiological state during the hospitalization, etc.) experienced before the discharge or felt when patients come back to their daily life. This implies the need for a better definition of the assessment time, based on specific intervals along with adequate time windows have to be defined (Wiklund, 2004) to better catch the different moods of patients. This seems to be related also to providers' ability in service recovery, considered as an important determinant of customer satisfaction. Thus, service recovery consists in providers' effort to solve a problem due to a service failure and to restore customer satisfaction (Lovelock \& Wirtz, 2007). These skills should be embedded in service corporate culture in order to generate patients' satisfaction, trust and loyalty.

Being developed according to a provider-led perspective, these patient surveys do not measure the quality of care, failing to consider fundamental elements such as being treated with respect or being involved in treatment decisions (Lee, Lindquist, Segal, \& Covinsky, 2006). In fact, these surveys miss to ask patients about their understanding, consciousness or knowledge about how to prevent future illness or what they learnt form the hospitalization that can positively affect their daily life and enhance their global well-being (Joiner \& Lusch, 2016). All the afore-mentioned arguments support that patients are usually considered as not qualified to evaluate medical performances, being not able to grasp the technical quality of provided services, but just to assess the received care. This is mainly due to the informative asymmetry, which traditionally affects health care and the service provider-patient relationship (Blomqvist, 1991; Barile et al., 2014; Ciasullo, Palumbo, \& Troisi, 2017). In fact, patients are presumed to be lacking of specific knowledge to evaluate health professionals' performance, while physicians' professional competences and power sometimes led them to exploit the results of surveys, constraining a participative evaluation of medical services built upon patients' perspective. Due to their limited technical knowledge, patients are considered more capable at assessing what they easily perceive or feel familiar. Therefore, they can just judge the functional quality (Meterko, Nelson, Rubin, Batalden, Berwick, Hays, \& Ware, 1990), being considered unable to evaluate technical quality or, in other words, physicians' competences and performances. In this direction, some studies underlined the essential role of healthscape (Hutton \& Richardson, 1995), defined as the sum of physical setting, infrastructures, facilities aesthetics, layout accessibility and cleanliness - that is tangible dimensions of health service -, on patients' judgement about the perceived overall 
service quality. According to this research path, patient surveys mainly focus on amenities and facilities (e.g. cleanliness, food, physical setting, provider manners, etc.), considering the value judgment on technical quality as dependent on functional quality. Factors related to the processes through which patients experience service - e.g. care accessibility, availability, continuity and effectiveness, etc. - (Keller, Yehia, Momplaisir, Eberhart, Share, \& Brady, 2014) as well as to the relationships - e.g. between administrative staff and patients; physicians and patients; nurses and patients, etc. - occurring during service experience come second to healthcare atmospherics.

This implies some sort of scientific determinism, according to the physical environment has a direct, one-to-one correspondence with behaviour, considered uniform across all individuals or social settings (Winkel, Saegert \& Evans, 2009). Thus empirical research does not confirm a positive correlation between tangible aspects of service healthscape and the overall patients' satisfaction (Sahoo \& Ghosh, 2016). Therefore, patients can be active contributors of knowledge and skills in care processes and physicians, general practitioners and nurses can learn from their experiences (Elg, Engström, Witell, \& Poksinska, 2012), improving service design and delivery, enhancing the whole healthscape. Echoes these findings, Gillard, Simons, Turner, Lucock, \& Edwards (2012) in their study on positive effects of patient generated knowledge on mental health service, in which the improvement of the technical dimension of service quality is discussed.

This shortsighted conduct is probably due to health organizations search for higher satisfaction ratings that led them focusing on "products", rather than on "service", or in other words failing to embrace a service-centered view. Patient surveys are also limited by their inability in defining the dimensions of patients' experience that they consider most valuable and their priorities for change, which might offer additional information to improve health services. Because of their structure, surveys do not grasp responses' subjectivity influenced by patients' personal judgments and beliefs (Hekkert et al., 2009).

Finally, personal traits (e.g. literacy, medical history, age, ethnicity, etc.), which highly vary from people to people, play a great influence on psychological disposition of patients. This emotional state arises from patients' reactions to peculiar feelings (e.g. pain, depression, anxiety, fear, etc.) (McColl-Kennedy, Hogan, Witell, \& Snyder, 2017) and from their un-involvement in services' designing and delivering.

Last but not least, patient surveys are administered just to patients, failing to involve their personal network (e.g. families, friends, peers, informal caregivers, etc.), even though the literature underlines that patient network represents a service health scape dense of value, which increase information flows, collaboration and cooperation necessary for improving health service's quality (Swan, 2009). In fact, experiences of families, peers, informal caregivers and others patients can encourage physicians, general practitioners and nurses to design more effective services as well as to trigger a positive perceptions of health care service quality (Zhao, Wang, \& Fan, 2015).

The limitations discussed above are grounded on a patient surveys foundational weakness related to the fact that they represent a passive form of establishing patients' views. This implies that are health providers to choose the indicators and the related items of patient satisfaction, failing in most cases in understanding patients' real needs and wants, because they do not catch perceptions, attitudes and experiences. Therefore, the role of patient is constrained to a mere information provider, which, on one hand, do not allow understanding the complexity and the high relational content at the core of health service. On the other, it fails to consider those interpersonal factors others than technical that might let a holistic understanding of patients (Donabedian, 1980; Berry \& Bendapudi, 2007).

In sum, patient surveys simplify patients' vision and attach them a passive role, being aimed at catching quality judgments and at limiting their participation in value creation. In other words, surveys grasp patient satisfaction according to an inside-out logic that points to improve the efficiency and the productivity of the existing care processes (Elg et al., 2012), but do not considers patients' point of view and the possible enhancement rising from their involvement in health services.

\section{The Application of Service Ecosystem Approach to Health Care}

\subsection{Service Ecosystems View}

The literature review performed highlights the application of ecosystems view to healthcare as an ideal "arrival point". Embracing a relational approach to the investigation of markets, which are intended as network of interacting actors, S-D Logic (Vargo and Lusch, 2004, 2008a) represents one of the most relevant service marketing and management theories. The framework is built upon an original way of thinking about value (co)creation in terms of service-for-service exchange. In S-D logic, service represents the form of exchange (Axiom1/FP1), while goods or services are just the way services are provided. This shed lights on the interactional nature of service, according to which the interactions occurring at least between two entities led to mutually create 
the service and its value. Therefore, value exchange is not as a mere economic transaction, but rather a service-for-service exchange in which actors directly and indirectly interact in a process of ongoing mutual adjustment. More in details, value of a service delivery lies in the continuous exchange of resources (mainly operant or intangible), which are provided through users' active participation. In this way, value is transformed and co-produced by customers or by users in general (Axiom2/ FP6). Users always co-create value, being intrinsically involved in value co-creation through several activities pointing to achieve a desired outcome (Payne et al., 2008; Vargo and Lusch, 2008a). In this sense, the centrality of users is emphasised as they are considered as both co-creators of value and resource integrators.

Stated in a different way, all social and economic actors are resource integrators (Axiom3/FP9). Actors interact in a network of non-linear, dynamic and changing relationships (Gummesson and Polese, 2009) - linked by service provisions (value propositions) - and in which co-creation lies upon a complex set of activities, mechanisms and processes. All these activities involve market-facing, public and private resources able to generate context-dependent value, which global service experience is influenced by the social context in which the service provision takes place (Axiom4/FP10). To grasp the dynamic structures of markets and to emphasize the role of social ties in value co-creation, Vargo and Lusch (2014) highlighted the centrality of institutions and institutional arrangements. Institutions (rules, norms, meanings, symbols, practices) boost the way resource integrators are coordinated and adjusted to each other's needs (Vargo \& Lusch, 2016). In other words, they are intended as coordinating mechanisms that guide, through institutional arrangements (higher-order assemblages of interrelated institutions), actors towards resource integration and service interactions (Axiom5/FP11).

S-D Logic has recently identified the service eco-system as the unit of analysis for value co-creation, being able to capture the network dynamics (Vargo \& Lusch, 2011; Wieland, Polese, Vargo, \& Lusch, 2012; Meynhardt, Chandler, \& Strathoff, 2016). In particular, Vargo, Maglio, \& Akaka, (2008) - considering organizations as networks of relationships - introduced service ecosystems, extending the concept of service systems (Maglio \& Spohrer, 2008). Thus, service systems are interacting entities and dynamic value co-creation configuration of resources, including people, organizations, shared information (language, laws, measures, methods) and technology, internally and externally connected to other service systems by value propositions or service provisions (Spohrer, Maglio, Bailey, \& Gruhl 2007). In this respect, service literature reinterpreted service systems as service eco-systems, focusing the attention on value co-creation, resource integration, emerging institutions and institutional arrangements (Åkesson, Edvardsson, \& Tronvoll, 2014) as well as on tangible and intangible artifacts ability in facilitating the value co-creation process (Lusch \& Spohrer, 2012). In other words, institutions (rules, norms, meanings, symbols, practices) acting as coordinating mechanisms guide, through institutional arrangements (higher-order assemblages of interrelated institutions), actors towards resource integration and service interactions (Axiom5/FP11).

Drawing on service ecosystems, Wieland et al. (2012) argued that to totally grasp their dynamic, evolving and complex nature, a system thought is needed to foster a holistic approach to its structural, behavioral and system features, and to grasp the interrelated, collaborative and dynamic nature of value co-creation (Barile \& Polese, 2010; Ng, Badinelli, Polese, Di Nauta, Löbler, \& Halliday, 2012).

Service eco-systems are layered and nested within three levels, ranging from the micro (individual) towards the meso (intermediary) and the macro (institutionalized) level (Chandler \& Vargo, 2011; Akaka \& Vargo, 2015). The micro level depicts service exchange as resource integration and value exchange, which directly and reciprocally occur between actors' dyads. The meso level represents the service system in which different service exchanges identify the network of institutions, while the macro level lies upon the combination of different institutions, characterized by specific institutional arrangements.

Interactions occurring at inter- and intra-levels trigger the change of all ecosystem levels (Akaka \& Vargo, 2014), amending the involved systems and making them dynamic and active over the time and the space (Lusch \& Vargo, 2014). Institutions and institutional arrangements make actors able to share a common view of the environment in which they interact, through common interests, cultural assumptions, evaluation methods and mental framework (Ciasullo, Cosimato, \& Palumbo, 2017). In this sense, institutional arrangements can be considered as the glue that hold together the nested levels which shape a service ecosystem and where actors choose and adjust their conduct to better face the possible conflicts rising from the connection of different institutional arrangements (Siltaloppi, Koskela-Huotari, \& Vargo, 2016). In other words, institutional arrangements frame resource integration, service exchange and value co-creation (Chandler \& Vargo, 2011), highlighting the value that resources have in a given place and at a specific period of time as well as how they can be accessed, adjusted and integrated according to specific contextual characteristics. It follows that actor's ability to access, adapt and integrate resources, formed by social context (Edvardsson, Tronvoll, \& Gruber, 2011; Akaka \& Vargo, 2015), influences value creation in service 
ecosystems. Therefore, it worth noting that the shaping of service ecosystems follows "an emergent process in which individual and collective agency, together with the institutional arrangements of the social system in which they operate, are mutually constitutive entities of that system" (Taillard, Peters, Pels, \& Mele, 2016).

\subsection{A Possible Rereading of Patient Surveys through Ecosystems View}

Patient surveys constrain value co-creation process within the dyad service provider-patient, failing to understand what value really means for patients. Indeed, the deterministic approach to quality assessment constrains resources integration, which is fundamental for value co-creation. As Joiner and Lusch (2016) stated “(...) answering the questions in the affirmative will create value for patient" (p. 27).

Embracing S-D Logic, health care service is a co-created service, laying on patients and service providers' involvement. Therefore, to co-create value actors have to be engaged in service-for-service exchange and in those interrelated interactions at the roots of resource integration. In fact, when actors are not engaged, resource cannot be integrated and value cannot be co-created, because actor engagement represents the micro foundation of value co-creation (Storbacka, Brodie, Böhmann, Maglio, \& Nenonen, 2016), supporting the interpretation and operationalization of the abstract nature of value co-creation.

Health care is characterized by a growing awareness about the need for patients' engagement in performing or doing activities and interactions pointing to improve health outcomes, patient care and to low costs (James, 2013). Patient engagement lies upon the assumption that health care service quality is mainly a patients' responsibility (Carman et al., 2010; Renedo, Komporozos-Athanasiou, \& Marston, 2017), which shapes their expectations, their role in service delivery and their service experience (Osborne, Radnor, \& Strokosch, 2016). However, health institutions, which provide rules, opportunities and resources, can enhance or constrain the rising of patients' proactive participation (Payne, Storbacka, \& Frow, 2008), making them responsible for their daily health care management.

McColl-Kennedy et al. (2012) defined health value co-creation a "benefit realized from integration of resources through activities and interactions with collaborators in the customer's service network" (p.1). Therefore, value is created when patients integrate their resources with those of service providers or even with those coming from outside the traditional health care service system, outspreading value creation outer than service provider-patient dyad. These resources come from private sources (e.g. family, friends, peers, etc.), market-facing sources (e.g. hospitals, clinics, informal caregivers, etc.), public sources (e.g. governing laws and regulations, transfer payments, etc.) and patient personal knowledge, experience and skills. To generate value-in-use, patients must be engaged in several activities, such as cooperating, sharing information, combining complementary therapies and co-learning. Finally, in their everyday life patients can integrate their resources collating information or combining complementary therapies. From the health care institutions perspective, the previous statements imply the need for enhancing patients' participation and experience with service, activating their sleeping resources (Palumbo, 2017) and forming value propositions able to attract actors to share their resources during collaborative activities and interactions (Frow, McColl-Kennedy, \& Payne, 2016).

At the micro level of a health care service ecosystem, co-creation involves clinicians and patients, who should work together with nurses and allied health professionals to design collaboratively a health service also involving families, friends and other patients dealing with the same disease. This implies that health service quality is co-created through co-production activities, including all health network actors, who become endogenous to health service design and delivery (Osborne et al., 2016).

Therefore, service co-production makes actors belonging to the service network real partners, whose passive compliance, described as the acquiescent acceptance of treatments and health professionals' advices, shift towards pragmatic adapting abilities, which trigger a virtuous learning circle that let share and co-create knowledge (Zhao et al., 2015; Tommasetti, Troisi, \& Vesci, 2017).

Health institutions have to promote health service providers' empowerment in order to make them open to patients' engagement in co-creating activities and interactions (Gill et al., 2011). This mutual engagement calls for a team-based approach to a shared decision-making, which involve networked actors (McColl-Kennedy et al., 2012) and encourage a participative ongoing redesign of treatments and the reconfiguration of professional team which lead to a holistic approach to patient care (Barry \& Edgman-Levitan, 2012). Teams reconfiguration should also involve multidisciplinary competences, making the empowered patients able to involve actors' others than the usual service providers, for example different medical experts such as physiologists, nutritionists, etc. (market-facing sources), who interact within patient personal network (private sources), and other support groups such as social services, social assistance, etc. (public sources). This implies the shifting towards the self-management of care, which engage patient, families and health teams, thanks to an open communication and a 
mutual understanding (Frow et al., 2016).

In sum, multiple direct and indirect interactions occur in value networks, where service delivery lies upon the mutual contribution of patients, service providers and their network (e.g. hospitals, clinics, first aid units, etc.) as well as patients and patients network (e.g. family, friend, peers, informal caregivers, etc.). For example, during a surgical procedure, service delivery rises from the contribution of medical professionals (e.g. surgeons, anesthesiologists, hospital porters, etc.), their network (e.g. pharmacists, radiologists, biologists, etc.), patients and their personal network (e.g. family, friends, peers, informal caregivers, etc.). Therefore, to shape a service ecosystem, value co-creation should be rooted on actors' interdependence and resources sharing (Wieland et al., 2016), that is "actor combination" (Storbacka et al., 2016). It stems from the engagement of different sets of actors, which spread from dyads towards triads and networks. This shifting fits better with a complex combination of actors here defined Many Humans-to-Many Humans (MH2MH). In addition, actor combination occurs across multiple settings, including for example traditional medical clinics, day-to-day personal interactions or virtual communities (Nambisan \& Nambisan, 2009). Actor combination implies the involvement of different actors, a wide scope of activities, the access, the sharing and the recombination of several resources, different attitudes towards medical services and changing expectations. In fact, the intertwined actors are engaged in dynamic, simultaneous and interdependent interactions, consequently the way they integrate resources, acting and interacting with each other, enable or constrain value co-creation. Therefore, the actor combination at the core of the health care service delivery represents the reason why the standardized and predefined quality measures at the roots of patient surveys are unable to catch patients' ideas and experiences. In other words, patient surveys inhibit the collaboration with health providers, fundamental to boost resource density, improve the available resources and increase value (Normann, 2001).

Drawing on health service complexity, service literature argued that actors (e.g. public organizations, third sector organizations, private firms, patients and families), with whom health organizations interact, contributing to shape a health care ecosystem with faded boundaries (Pinho, Beirão, Patrício, \& Fisk, 2014; Frow et al., 2016; Beirao, Patrício, \& Fisk, 2017, Ciasullo et al., 2017). Actors' collaboration is essential to increase resources density, their availability and the value they contribute to create (Normann, 2001). Thus, actors constantly create and recreate emergent A2A structures (Lusch \& Nambisan, 2015), lying upon different activities enacted within the health care service system, which form and reform mutual links able to enhance health outcomes and patient satisfaction. Therefore, a systems approach seems to be fundamental to understand the complexity of health care service, based on value networks (e.g. $\mathrm{MH} 2 \mathrm{MH}$ ) which learn from the experience and tend to improve system viability. Being embedded in a service ecosystem, actor' should be disposed to share and apply their resources, influencing their availability and ecosystem ability to adapt its configuration to a complex and ever-changing environment (Ciasullo, 2017). Therefore, the search for some sort of stability calls for institutionalization processes in which the rules are co-developed and shared, becoming an essential coordination mechanism (Lusch, Vargo, \& Gustafsson, 2016). Thus, patient surveys represent a rule of conduct that constrains actors' adaptability, failing to consider and articulate patients' quality perception emerging from interactions, use and engagement in service value network.

The attempt to assign a score to health service quality, through statistic methods, miss to consider that numbers do not offer information about the intricate nature of this service. Patient surveys represent a real threat for ecosystem viability, constraining value co-creation or "infecting" the whole ecosystem, making patients unsatisfied, leading health organizations to concentrate their efforts towards attributes of health service far from patients' expectations and generating a chain of individuals' dissatisfactions steaming from patients and spreading to the other ecosystem actors. Thus, how can a patient survey grasp the health care service complexity?

\section{Theoretical and Managerial Implications}

Embracing a service eco-system perspective, the study critically analyzed the traditional and most whispered tools for quality measurement in healthcare setting. The above-mentioned reinterpretation offered the following insights.

The first one is the reconceptualization of quality as value. In line with extant research, "old" quality management models seem to be gradually shifted towards a broaden system view (Chen, Tee, Chortos, Schwartz, Tse, Lipomi, ... $\&$ Bao, 2014). For this reason, contemporary service organizations should not focus just on the assessment of individual quality and satisfaction, but should investigate the total quality of at ecosystem level to achieve synergistic effects. As the inadequacy of patient survey reveals, to understand what value really means for both patients and service providers, in healthcare ecosystems value should be assessed through an integrated set of qualitative and quantitative techniques. Indeed, the quality, performance, outcome of a service process is shaped primarily by users' expectations, their passive or active or passive role in service delivery and their subsequent 
experience of it.

Rethinking patient surveys satisfaction tools according to a service ecosystem perspective should contribute to make them as inclusive as possible and able to define the role of each ecosystem actor (e.g. patient, families, peers, physicians, non-medical staff, etc.) in service interactions. This implies that the tools for the assessment of patient satisfaction will be able to highlight the different moments in which service is exchanged and to go beyond the evaluation of the mere healthscape and the personnel involved in care paths.

The reinterpretation of healthcare as an ecosystem requires an in-depth analysis of institutions as underlying drivers for engagement and as the foundational units to detect value co-creation behaviors. According to some recent calls for research (Barile, Lusch, Reynoso, Saviano, \& Spohrer, 2016; Lusch et al. 2016), understanding the enablers of service exchanges is essential for both researchers and managers. Among these drivers, Meynhardt et al. (2016) maintained that institutional changes can have a long-run influence on service ecosystems viability, triggering ecosystem evolution (Koskela-Huotari, Edvardsson, Jonas, Sörhammar, \& Witell, 2016). However, to understand the role of institutions - in driving the interactions and resource sharing at the roots of value co-creation - institutional arrangements should be investigated empirically. Thus, a systems approach based on institutional arrangements investigation might contribute to reveal the potential negative effect of co-destructive behaviours. Mangers can foster engagement redesigning treatment programs and reconfiguring professional teams to gain a value-based approach to patient care (McColl-Kennedy et al., 2012; Barry \& Edgman-Levitan, 2012; Frow et al., 2016). To do this, institutions should define specific institutional arrangements able to foster patient empowerment, for example engaging them in different practices and moments of care in order to avoid the emergence the information asymmetries that constrain value co-creation (Barile et al., 2014). Institutions should support a service-oriented rethinking of patient surveys, based on those mutual initiatives and tools able to engage actors in the nourishing of health service eco-system viability. Furthermore, to avoid the emergence of chaotic and hostile circumstances, the implementation of informative systems (non-living actors) (Wieland, Vargo \& Akaka, 2016) should be encouraged to get a constant and real-time feedback about patients and health providers' experiences. Thus, this feedback should balance information flows and their possible effect on the eco-system.

In line with theoretical issues, future empirical investigations might reframe the traditional tools for quality assessment investigating how 'value' is co-created and spread within health care organizations. This calls for mixed method (Harrison \& Reilly, 2011) able to grasp, through an exploratory approach based on ethnographic research, how interactions, resource integration and engagement practices can boost value co-creation. After the classification of different co-creation activities, a quantitative evaluation of quality and value co-creation practices should be conducted. In this way, managers could better define specific involvement strategies, based on different degrees of users' engagement and on the different activities of resource integration. In this direction, the advancements proposed by the Evidence Based Design (EBD) to investigate complex ecological systems, such as healthcare, can offer a fertile ground for improving care quality and experience for and together with healthcare providers, patients and their network (e.g. families, peers, friends, informal caregivers) (Beker, Bonaiuto, Bilotta \& Bonness, 2011).

\section{Final Remarks}

Starting from the reconceptualization of healthcare as a service ecosystem, in line with the last developments proposed in S-D logic, the work introduces and discusses the need to renew the traditional tools to assess patient satisfaction. The adoption of a standardized technique constrains a deep understanding of the active role that patients play in service interactions and limiting the understanding of how actor's engagement influence on value co-creation. The analysis of patient surveys revealed that an ingrained good-orientation (Gummesson, 2017) characterized this assessment tools. Therefore, quality and its measurement should be reinterpreted, according to the broader notion of value, and aligned with service eco-systems perspective, which puts actor disposition at the core of value co-creation.

Health institutions still fail in moderating patients-providers' interactions, especially when intended to evaluate patient satisfaction. Being wrong institutional arrangements, patient surveys can constrain value co-creation, inhibiting service ecosystem viability infecting it.

A service eco-system perspective (Vargo \& Lusch, 2017) might support health managers in overcoming the intrinsic limitations of patient surveys, facing the potential negative effects of these tools on service quality and on the well-being of eco-system actors. In this sense, service eco-system perspective led to go beyond the traditional good-dominant view and to adopt a systems view able to face health care complexity (Joiner \& Lusch, 2016; Barile et al., 2016), emphasizing the dynamic interactions that hold together eco-system actors. In doing so, institutions play a key role in defining, the "rules of the game" that institutionalize health service ecosystem actors disposition 
to interact and co-create value. Thus, this should prevent disruptive or infective behaviours of providers and patients, making them really involved in service-for-service exchange.

Further research is needed for better understand not only how organizations engage patients and facilitate value co-creation practice but also if and how, assuming a service eco-system perspective, value co-creation practices implemented in a specific service area can be applied to other service settings.

\section{References}

Akaka, M. A., \& Vargo, S. L. (2014). Technology as an operant resource in service (eco) systems. Information Systems and e-Business Management, 12(3), 367-384. https://dx.doi.org/10.1007/s10257-013-0220-5

Akaka, M. A., \& Vargo, S. L. (2015). Extending the context of service: from encounters to ecosystems. Journal of Services Marketing, 29(6/7), 453-462. https://dx.doi.org/10.1108/JSM-03-2015-0126

Åkesson, M., Edvardsson, B., \& Tronvoll, B. (2014). Customer experience from a self-service system perspective. Journal of Service Management, 25(5), 677-698. https://dx.doi.org/10.1108/JOSM-01-2013-0016

Badcott, D. (2005). The expert patient: valid recognition or false hope?, Medicine, Health Care Philosophy, 8(2), 173-178. https://dx.doi.org/10.1007/s11019-005-2275-7

Barile, S., \& Polese, F. (2010). Linking viable systems approach and many-to-many network approach to service-dominant logic and service science. International Journal of Quality and Service Sciences, 2(1), 23-42. https://dx.doi.org/10.1108/17566691011026586

Barile, S., Saviano, M., \& Polese, F. (2014). Information asymmetry and co-creation in health care services. Australasian Marketing Journal (AMJ), 22(3), 205-217. https://dx.doi.org/10.1108/JOSM-09-2015-0268

Barry, M.J., \& Edgman-Levitan, S. (2012). Shared decision making - the pinnacle of patient-centred care. New England Journal of Medicine, 366(9), 780-781. https://dx.doi.org/10.1056/NEJMp1109283

Becker, F., Bonaiuto, M., Bilotta, E., \& Bonnes, M. (2011). Integrated healthscape strategies: An ecological approach to evidence-based design. HERD: Health Environments Research \& Design Journal, 4(4), 114-129. https://dx.doi.org/10.1177/193758671100400409

Beirão, G., Patrício, L., \& Fisk, R.P. (2017). Value cocreation in service ecosystems: Investigating health care at the micro, meso, and macro levels. Journal of Service Management, 28(2), 227-249. https://dx.doi.org/10.1108/JOSM-11-2015-0357

Bendapudi, N., \& Leone, R.P. (2003). Psychological implications of customer participation in co-production. Journal of marketing, 67(1), 14-28. https://dx.doi.org/10.1509/jmkg.67.1.14.18592

Berry, L., Carbone, L., \& Haeckel, S. (2002), Managing the total customer experience, MIT Sloan Management Review, 43(3), 84-90. https://dx.doi.org/ 10.1086/208911

Berry, L.L., \& Bendapudi, N. (2007). Health care: A fertile field for service research. Journal of Service Research, 10(2), 111-122. https://dx.doi.org/10.1177/1094670507306682

Blomqvist, $\AA$. (1991). The doctor as double agent: Information asymmetry, health insurance, and medical care. Journal of Health Economics, 10(4), 411-432. https://dx.doi.org/10.1377/hlthaff.2009.0296

Carman, K.L., Maurer, M., Yegian, J.M., Dardess, P., McGee, J., Evers, M., \& Marlo, K.O. (2010). Evidence that consumers are skeptical about evidence-based health care. Health Affairs, 29(7), 1400-1406. https://dx.doi.org/10.1377/hlthaff.2009.0296

Carter, J. C., \& Silverman, F. N. (2016). Using HCAHPS data to improve hospital care quality. The TQM Journal, 28(6), 974-990. https://dx.doi.org/10.1108/TQM-09-2014-0072

Chakraborty, S., Bhattacharya, S., \& Dobrzykowski, D.D. (2014). Impact of supply chain collaboration on value co-creation and firm performance: a healthcare service sector perspective. Procedia Economics and Finance, 11, 676-694. https://dx.doi.org/10.1016/S2212-5671(14)00233-0

Chandler, J.D., \& Vargo, S.L. (2011). Contextualization and value-in-context: How context frames exchange. Marketing theory, 11(1), 35-49. https://dx.doi.org/10.1177/1470593110393713

Chen, L. Y., Tee, B. C. K., Chortos, A. L., Schwartz, G., Tse, V., Lipomi, D. J., ... \& Bao, Z. (2014). Continuous wireless pressure monitoring and mapping with ultra-small passive sensors for health monitoring and critical care. Nature communications, 5(1), 5028. https://dx.doi.org/10.1038/ncomms6028

Ciasullo, M.V. (2017). Introduction to the special issue on managing service innovation and quality: a service 
ecosystem perspective. The TQM Journal, 29(6), 762-766. https://dx.doi.org/10.1108/TQM-08-2017-0089

Ciasullo, M.V., Cosimato, S., \& Douglas, A. (2017). Customer-centric service innovation in health care: findings from a case study. Sinergie Italian Journal of Management, 104, 155-176. https://dx.doi.org/10.7433/s104.2017.08

Ciasullo, M.V., Cosimato, S., \& Palumbo, R. (2017). Improving health care quality: the implementation of whistleblowing. The TQM Journal, 29(1), 167-183. https://dx.doi.org/10.1108/TQM-06-2016-0051

Ciasullo, M.V., Cosimato, S., \& Palumbo, R. (2017). Value Co-creation in the Health Service Ecosystems: The Enabling Role of Institutional Arrangements. International Business Research, 10(12), 222-238. https://doi.org/10.5539/ibr.v10n12p222

Ciasullo, M. V., Palumbo, R., \& Troisi, O. (2017). Reading public service co-production through the lenses of requisite variety. International Journal of Business and Management, 12(2), 1. https://dx.doi:10.5539/ijbm.v12n2p1

Cooper, H. M. (1998). Synthesizing research: A guide for literature reviews, 2. Sage, Thousand Oaks, CA. https://dx.doi.org/10.2307/3172876.

Cooper, H. (2010). Research Synthesis and Meta-Analysis: A Step-by-Step Approach, 4th edition. Sage, Thousand Oaks, CA. https://dx.doi.org/10.4135/9781483348858.n11

Dagger, T.S., Sweeney, J.C., \& Johnson, L.W. (2007). A hierarchical model of health service quality: scale development and investigation of an integrated model. Journal of service research, 10(2), 123-142. https://dx.doi.org/10.1177/1094670507309594

Dellande, S., Gilly, M. C., \& Graham, J. L. (2004). Gaining compliance and losing weight: The role of the service provider in health care services. Journal of Marketing, 68(3), 78-91. https://dx.doi.org/10.1509/jmkg.68.3.78.34764

Donabedian, A. (1980). Methods for deriving criteria for assessing the quality of medical care. Medical care review, 37(7), 653.

Dowrick, C. (1995). Does testing for depression influence diagnosis or management by general practitioners. Family Practice, 12, 461-465. https://dx.doi.org/10.1093/fampra/12.4.461

Draper, M., Cohen, P., \& Buchan, H. (2001). Seeking consumer views: what use are results of hospital patient satisfaction surveys? International Journal for Quality in Health Care, 13(6), 463-468. https://dx.doi.org/10.1093/intqhe/13.6.463

Dufrene, R.L. (2000). An evaluation of a patient satisfaction survey: validity and reliability. Evaluation and Program Planning, 23(3), 293-300. https://dx.doi.org/10.1016/S0149-7189(00)00015-X

Edvardsson, B., Tronvoll, B., \& Gruber, T. (2011). Expanding understanding of service exchange and value co-creation: a social construction approach. Journal of the Academy of Marketing Science, 39(2), 327-339. https://dx.doi.org/10.1007/s11747-010-0200-y

Eiriz, V., \& António Figueiredo, J. (2005). Quality evaluation in health care services based on customer-provider relationships. International journal of health care quality assurance, 18(6), 404-412. https://dx.doi.org/10.1108/09526860510619408

Elg, M., Engström, J., Witell, L., \& Poksinska, B. (2012). Co-creation and learning in health-care service development. Journal of Service Management, 23(3), 328-343. https://dx.doi.org/10.1108/09564231211248435

Fallowfield, L. J., Hall, A., Maguire, G. P., Baum, M. (1990). Psychological out-comes of different treatment policies in women with early breast cancer outside a clinical trial. Business Management Journal, 301(6752), 575-580.

Fitzpatrick, R. (1991). Surveys of patients satisfaction: I -- important general considerations. British Medical Journal, 302(6781), 887. https://dx.doi.org/10.1136/bmj.302.6781.887

Frow, P., McColl-Kennedy, J. R., \& Payne, A. (2016). Co-creation practices: Their role in shaping a health care $\begin{array}{lllll}\text { ecosystem. Industrial Marketing 24-39. } & \text { Manement, }\end{array}$ https://dx.doi.org/10.1016/j.indmarman.2016.03.007

Gilbert, G. R., \& Veloutsou, C. (2006). A cross-industry comparison of customer satisfaction. Journal of Services Marketing, 20(5), 298-308. https://dx.doi.org/10.1108/08876040610679918 
Gilbert, G. R., Veloutsou, C., Goode, M. M., \& Moutinho, L. (2004). Measuring customer satisfaction in the fast food industry: a cross-national approach. Journal of Services Marketing, 18(5), 371-383. https://dx.doi.org/10.1108/08876040410548294

Gill, L., \& White, L. (2009). A critical review of patient satisfaction. Leadership in Health Services, 22(1), 8-19. https://dx.doi.org/10.1108/17511870910927994

Gill, L., White, L., \& Cameron, I. D. (2011). Service co-creation in community-based aged healthcare. Managing Service Quality: An International Journal, 21(2), 152-177. https://dx.doi.org/10.1108/09604521111113447

Gillard, S., Simons, L., Turner, K., Lucock, M., \& Edwards, C. (2012). Patient and public involvement in the coproduction of knowledge: reflection on the analysis of qualitative data in a mental health study. Qualitative Health Research, 22(8), 1126-1137. https://dx.doi.org/10.1177/1049732312448541

Godolphin, W. (2009). Shared decision-making. Healthcare Quarterly, 12(August), 186-190. https://dx.doi.org/10.12927/hcq.2009.20947

González-Valentín, A., Padín-López, S., \& de Ramón-Garrido, E. (2005). Patient satisfaction with nursing care in a regional university hospital in southern Spain. Journal of Nursing Care Quality, 20(1), 63-72. https://dx.doi.org/10.1097/00001786-200501000-00011

Graneheim, U. H., \& Lundman, B. (2004). Qualitative content analysis in nursing research: concepts, procedures and measures to achieve trustworthiness. Nurse education today, 24(2), 105-112. https://dx.doi.org/10.1016/j.nedt.2003.10.001

Gummesson, E. (2017). From relationship marketing to total relationship marketing and beyond. Journal of services marketing, 31(1), 16-19. https://dx.doi.org/10.1108/JSM-11-2016-0398

Harrison, R. L., \& Reilly, T. M. (2011). Mixed methods designs in marketing research. Qualitative Market Research: An International Journal, 14(1), 7-26. https://dx.doi.org/10.1108/13522751111099300

Hawthorne, G., Sansoni, J., Hayes, L. M., Marosszeky, N., \& Sansoni, E. (2006). Measuring patient satisfaction with incontinence treatment. Report, Centre for Health Service Development, University of Wollongong and the Department of Psychiatry, 8, p.1-103. 10.1016/j.jclinepi.2013.12.010.

Heidegger, T., Saal, D., \& Nübling, M. (2013). Patient satisfaction with anesthesia-Part 1: satisfaction as part of outcome-and what satisfies patients. Anaesthesia, 68(11), 1165-1172. https://doi.org/10.2147/AA

Heidegger, T., Saal, D., \& Nuebling, M. (2006). Patient satisfaction with anaesthesia care: what is patient satisfaction, how should it be measured, and what is the evidence for assuring high patient satisfaction? Best Practice \& Research Clinical Anaesthesiology, 20(2), 331-346. 10.1016/j.bpa.2005.10.010

Hekkert, K. D., Cihangir, S., Kleefstra, S. M., van den Berg, B., \& Kool, R. B. (2009). Patient satisfaction revisited: a multilevel approach. Social science \& medicine, 69(1), 68-75. https://dx.doi.org/10.1016/j.socscimed.2009.04.016

Holman, H., \& Lorig, K. (2000). Patients as partners in managing chronic disease. BMJ: British Medical Journal, 320(7234), p.526. https://dx.doi.org/10.1136/bmj.320.7234.526

Hutton, J. D., \& Richardson, L. D. (1995). Healthscapes: the role of the facility and physical environment on consumer attitudes, satisfaction, quality assessments, and behaviors. Health Care Management Review, 20(2), 48-61. https://dx.doi.org/10.1097/00004010-199521000-00008

James, W. (2013). The principles of psychology. Read Books Ltd, Redditch, UK. https://dx.doi.org/10.1037/11059-000

Jenkinson, C., Coulter, A., Bruster, S., Richards, N., \& Chandola, T. (2002). Patients' experiences and satisfaction with health care: results of a questionnaire study of specific aspects of care. Qual Saf Health Care, 11(4), 335-339. 10.1136/qhc.11.4.335

Joiner, K., \& Lusch, R. (2016). Evolving to a new service-dominant logic for health care. Innovation and Entrepreneurship in Health, 3, 25-33.10.2147/IEH

Kassarjian, H. H. (1977). Content analysis in consumer research. Journal of consumer research, 4(1), 8-18.

Kazis L.E., Callahan L.F., Meenan R.F. \& Pincus T. (1990). Health status reports in the care of patients with rheumatoid

arthritis. Journal of Clinical https://dx.doi.org/10.1016/0895-4356(90)90025-K

Epidemiology, $\quad$ 43(11),

1243-1253. 
Keller, S. C., Yehia, B.R., Momplaisir, F.O., Eberhart, M.G., Share, A., \& Brady, K.A. (2014). Assessing the overall quality of health care in persons living with HIV in an urban environment. AIDS patient care and STDs, 28(4), 198-205. https://dx.doi.org/10.1089/apc.2014.0001

Kleefstra, S.M., Kool, R.B., Veldkamp, C.M.A., Winters-van der Meer, A.C.M., Mens, M.A.P., Blijham, G.H., \& de Haes, J.C J.M. (2010). A core questionnaire for the assessment of patient satisfaction in academic hospitals in The Netherlands: development and first results in a nationwide study. Qual Saf Health Care, 19(5), e24-e24. https://dx.doi.org/10.1136/qshc.2008.030825

Koskela-Huotari, K., Edvardsson, B., Jonas, J. M., Sörhammar, D., \& Witell, L. (2016). Innovation in service ecosystems - Breaking, making, and maintaining institutionalized rules of resource integration. Journal of Business Research, 69(8), 2964-2971. https://dx.doi.org/10.1016/j.jbusres.2016.02.029

Krippendorff, K., \& Bock, M. A. (2009). The content analysis reader. Sage, Thousand Oaks, CA. oclc/191846849

LaVela, S. L., \& Gallan, A. (2014). Evaluation and measurement of patient experience. Patient Experience Journal, 1(1), 28-36. 10.1186/1472.

Lee, S.J., Lindquist, K., Segal, M. R., \& Covinsky, K. E. (2006). Development and validation of a prognostic index for 4-year mortality in older adults. Jama, 295(7), 801-808. https://dx.doi.org/10.1001/jama.295.7.801

Locker, D., \& Dunt, D. (1978). Theoretical and methodological issues in sociological studies of consumer satisfaction with medical care. Social Science \& Medicine. Part A: Medical Psychology \& Medical Sociology, 12, 283-292. https://dx.doi.org/10.1016/0271-7123(78)90067-6

López-Jornet, P., \& Camacho-Alonso, F. (2010). Quality of life in patients with oral lichen planus. Journal of evaluation in clinical practice, 16(1), 111-113. https://doi.org/10.1111/j.1365-2753.2009.01124.x

Lovelock C. H., \& Wirtz, J. (2007). Services marketing (6th Ed.), Pearson Prentice-Hall, Upper Saddle River, NJ. 10.1.1.475.461

Lusch, R. F., \& Nambisan, S. (2015). Service innovation: A service-dominant logic perspective. MIS quarterly, 39(1), 155. https://dx.doi.org/10.25300/MISQ/2015/39.1.07

Lusch, R. F., \& Spohrer, J. C. (2012). Evolving service for a complex, resilient, and sustainable world. Journal of Marketing Management, 28(13-14), 1491-1503. https://dx.doi.org/10.1080/0267257X.2012.744801

Lusch, R. F., \& Vargo, S. L. (2014). Service-dominant logic: Premises, perspectives, possibilities. Cambridge University Press, Cambridge, MC. https://dx.doi.org/10.1017/CBO9781139043120

Lusch, R. F., Vargo, S. L., \& Gustafsson, A. (2016). Fostering a trans-disciplinary perspectives of service ecosystems. Journal of Business Research, 69(8), 2957-2963. https://dx.doi.org/10.1016/j.jbusres.2016.02.028

Maglio, P. P., \& Spohrer, J. (2008). Fundamentals of service science. Journal of the academy of marketing science, 36(1), 18-20. https://dx.doi.org/10.1007/s11747-007-0058-9

Mazonson P. D., Mathias S. D., Fifer S. K., Beusching D. P., \& Malek, P. (1996). The mental health patient profile: does it change primary care physicians practice patterns? Journal of the American Board of Family Practice, 9(5), 336-345. https://dx.doi.org/10.3122/jabfm.9.5.336.

McColl-Kennedy, J. R., Hogan, S. J., Witell, L., \& Snyder, H. (2017). Cocreative customer practices: Effects of health care customer value cocreation practices on well-being. Journal of Business Research, 70, 55-66. https://dx.doi.org/10.1016/j.jbusres.2016.07.006

McColl-Kennedy, J. R., Vargo, S. L., Dagger, T. S., Sweeney, J. C., \& Kasteren, Y. V. (2012). Health care customer value cocreation practice styles. Journal of Service Research, 15(4), 370-389. https://dx.doi.org/10.1177/1094670512442806

McKinley, R. K., Manku-Scott, T., Hastings, A. M., French, D. P., \& Baker, R. (1997). Reliability and validity of a new measure of patient satisfaction with out of hours primary medical care in the United Kingdom: development of a patient questionnaire. Bmj, 314(7075), 193. https://dx.doi.org/10.1136/bmj.314.7075.193

Meterko, M., Nelson, E. C., Rubin, H. R., Batalden, P., Berwick, D. M., Hays, R. D., \& Ware, J. E. (1990). Patient judgments of hospital quality: report of a pilot study. Medical care, 28(9), S1-S56. https://dx.doi.org/10.1097/00005650-199009001-00003

Meynhardt, T., Chandler, J. D., \& Strathoff, P. (2016). Systemic principles of value co-creation: Synergetics of value and service ecosystems. Journal of Business Research, 69(8), 2981-2989. 
https://dx.doi.org/10.1016/j.jbusres.2016.02.031

Moher, D., Liberati, A., Tetzlaff, J., \& Altman, D. G. (2009). Preferred reporting items for systematic reviews and meta-analyses: the PRISMA statement. Annals of Internal Medicine, 151(4), 264-269. https://dx.doi.org/10.1016/j.jclinepi.2009.06.005

Moore, A. A., Siu, A. L., Partridge, J. M., Hays, R. D., \& Adams, J. (1997). A randomised trial of office based screening for common problems in older persons. The American Journal of Medicine, 102, 371-378. https://dx.doi.org/10.1016/S0002-9343(97)00089-2

Mulrow, C. D. (1994). Systematic reviews: rationale for systematic reviews. British Medical Journal, 309(6954), 597-599. https://doi.org/10.1136/bmj.309.6954.597

Nambisan, P., \& Nambisan, S. (2009). Models of consumer value cocreation in health care. Health Care Management Review, 34(4), 344-354. https://dx.doi.org/10.1097/HMR.0b013e3181abd528

Ng, I.C.L., Badinelli, R., Polese, F., Di Nauta, P., Löbler, H., \& Halliday, S. (2012). S-D logic research directions and opportunities: The perspective of systems, complexity and engineering. Marketing Theory, 12(2), 213-217. https://dx.doi.org/10.1177/1470593111429519

Normann, R. (2001). Reframing business: When the map changes the landscape. John Wiley \& Sons, London, UK. https://dx.doi.org/10.1080/14719037.2017.1350461

Osborne, S.P., Radnor, Z., \& Strokosch, K. (2016). Co-Production and the Co-Creation of Value in Public Services: A suitable case for treatment? Public Management Review, 18(5), 639-653. https://dx.doi.org/10.1080/14719037.2015.1111927

Pai, P.Y., \& Chary, T.S. (2013). Dimensions of hospital service quality: A critical review: Perspective of patients from global studies. International journal of health care quality assurance, 26(4), 308-340. https://dx.doi.org/10.1108/09526861311319555

Palumbo, R. (2017). The Role of Health Literacy in Empowering Patients. In The Bright Side and the Dark Side of Patient Empowerment (63-78). Springer International Publishing, London. https://dx.doi.org/10.1007/978-3-319-58344-0_4

Palumbo, R., Cosimato, S., \& Tommasetti, A. (2017). Dream or reality? A recipe for sustainable and innovative health care ecosystems. The TQM Journal, 29(6), 847-862. https://dx.doi.org/10.1108/TQM-02-2017-0023

Pascoe, G. C. (1983). Patient satisfaction in primary health care: A literature review and analysis. Evaluation and program planning, 6(3-4), 185-210. https://dx.doi.org/10.1016/0149-7189(83)90002-2

Payne, A. F., Storbacka, K., \& Frow, P. (2008). Managing the co-creation of value. Journal of the academy of marketing science, 36(1), 83-96. https://dx.doi.org/10.1007/s11747-007-0070-0

Perneger, T. V. (2004). Adjustment for patient characteristics in satisfaction surveys. International Journal for Quality in Health Care, 16(6), 433-435. https://dx.doi.org/10.1093/intqhe/mzh090

Pinho, N., Beirão, G., Patrício, L., \& Fisk, P. R. (2014). Understanding value co-creation in complex services with many actors. Journal of Service Management, 25(4), 470-493. https://dx.doi.org/10.1108/JOSM-02-2014-0055

Plé, L., \& Chumpitaz Cáceres, R. (2010). Not always co-creation: introducing interactional co-destruction of value in service-dominant logic. Journal of Services Marketing, 24(6), 430-437. https://dx.doi.org/10.1108/08876041011072546

Polese, F., \& Capunzo, M. (2013). The determinants of translational medicine success-A managerial contribution. Translational Medicine UniSa, 6, p.29. Retreived from: https://www.ncbi.nlm.nih.gov/pmc/articles/PMC3829794/ PMCID: PMC3829794

Porter, M. E. (2010). What is value in health care? New England Journal of Medicine, 363(26), 2477-2481. https://dx.doi.org/10.1056/NEJMp1011024

Quintana, J. M., Escobar, A., Arostegui, I., Bilbao, A., Azkarate, J., Goenaga, J. I., \& Arenaza, J. C. (2006). Health-related quality of life and appropriateness of knee or hip joint replacement. Archives of internal medicine, 166(2), 220-226. https://dx.doi.org/10.1001/archinte.166.2.220

Ransom, S., Jacobsen, P. B., Schmidt, J. E., \& Andrykowski, M. A. (2005). Relationship of problem-focused coping strategies to changes in quality of life following treatment for early stage breast cancer. Journal of Pain and Symptom Management, 30(3), 243-253. https://dx.doi.org/10.1016/j.jpainsymman.2005.03.013 
Rathert, C., Wyrwich, M. D., \& Boren, S. A. (2013). Patient-centered care and outcomes a systematic review of the literature. Medical Care Research and Review, 70(4), 351-379. https://dx.doi.org/10.1177/1077558712465774

Renedo, A., Komporozos-Athanasiou, A., \& Marston, C. (2017). Experience as evidence: The dialogic construction of health professional knowledge through patient involvement. Sociology. https://dx.doi.org/10.1177/0038038516682457

Sahoo, D., \& Ghosh, T. (2016). Healthscape role towards customer satisfaction in private healthcare. International Journal of Health Care Quality Assurance, 29(6), 600-613. https://dx.doi.org/10.1108/IJHCQA-05-2015-0068

Siltaloppi, J., Koskela-Huotari, K., \& Vargo, S.L. (2016). Institutional complexity as a driver for innovation in service ecosystems. Service Science, 8(3), 333-343. https://dx.doi.org/10.1287/serv.2016.0151

Sitzia, J., \& Wood, N. (1997). Patient satisfaction: a review of issues and concepts. Social science \& medicine, 45(12), 1829-1843. https://dx.doi.org/10.1016/S0277-9536(97)00128-7

Spohrer, J., Maglio, P.P., Bailey, J., \& Gruhl, D. (2007). Steps toward a science of service systems. Computer, 40(1), 71. https://dx.doi.org/10.1109/MC.2007.33

Storbacka, K., Brodie, R.J., Böhmann, T., Maglio, P.P., \& Nenonen, S. (2016). Actor engagement as a microfoundation for value co-creation. Journal of Business Research, 69(8), 3008-3017. https://dx.doi.org/10.1016/j.jbusres.2016.02.034

Swan, M. (2009). Emerging patient-driven health care models: an examination of health social networks, consumer personalized medicine and quantified self-tracking. International journal of environmental research and public health, 6(2), 492-525. https://dx.doi.org/10.3390/ijerph6020492

Taillard, M., Peters, L. D., Pels, J., \& Mele, C. (2016). The role of shared intentions in the emergence of service ecosystems. Journal of Business Research, 2972-2980. https://dx.doi.org/10.1016/j.jbusres.2016.02.030

Tommasetti, A., Troisi, O., \& Cosimato, S. (2014). Patient empowerment and health online community: two ways to give the new viability doctor-patient relationship= Cooperación y intercambio de conocimiento en la era de Internet: dos maneras de dar nueva viabilidad a la relación médico-paciente. Comunitania. Revista Internacional de Trabajo Social y Ciencias Sociales, (8), 9-23. https://doi.org/10.5944/comunitania.8.1

Tommasetti, A., Troisi, O., \& Vesci, M. (2017). Measuring customer value co-creation behavior: Developing a conceptual model based on service-dominant logic. Journal of Service Theory and Practice, 27(5), 930-950. https://doi.org/10.1108/JSTP-10-2015-0215

Tranfield, D., Denyer, D., \& Smart, P. (2003). Towards a methodology for developing evidence-informed management knowledge by means of systematic review. British Journal of Management, 14(3), 207-222. https://dx.doi.org/10.1111/1467-8551.00375.

Turris, S. A. (2005). Unpacking the concept of patient satisfaction: A feminist analysis. Journal of advanced nursing, 50(3), 293-298. https://dx.doi.org/10.1111/j.1365-2648.2005.03392.x

Vargo, S. L., Maglio, P. P., \& Akaka, M. A. (2008). On value and value co-creation: A service systems and service logic perspective. European Management Journal, 26(3), 145-152. https://dx.doi.org/10.1016/j.emj.2008.04.003

Vargo, S. L., \& Lusch, R. F. (2016). Institutions and axioms: an extension and update of service-dominant logic. Journal of the Academy of Marketing Science, 44(1), 5-23. https://dx.doi.org/10.1007/s11747-015-0456-3

Vargo, S. L., \& Lusch, R. F. (2004). Evolving to a new dominant logic for marketing. Journal of Marketing, 68(1), 1-17. https://dx.doi.org/10.1509/jmkg.68.1.1.24036

Vargo, S. L., \& Lusch, R. F. (2008). Service-dominant logic: continuing the evolution. Journal of the Academy of Marketing Science, 36(1), 1-10. https://dx.doi.org/10.1007/s11747-007-0069-6

Vargo, S. L., \& Lusch, R. F. (2011). It's all B2B... and beyond: Toward a systems perspective of the market. Industrial Marketing Management, 40(2), 181-187. https://dx.doi.org/10.1016/j.indmarman.2010.06.026

Vargo, S. L., \& Lusch, R. F. (2014). Inversions of service-dominant logic. Marketing Theory, 14(3), 239-248. https://dx.doi.org/10.1177/1470593114534339

Vargo, S. L., \& Lusch, R. F. (2017). Service-dominant logic 2025. International Journal of Research in Marketing, 
34(1), 46-67. https://dx.doi.org/10.1016/j.ijresmar.2016.11.001

Vredenburg, J., \& Bell, S. J. (2014). Variability in health care services: the role of service employee flexibility. Australasian Marketing Journal (AMJ), 22(3), 168-178. https://dx.doi.org/10.1016/j.ausmj.2014.08.001

Wagner A. K., Ehrenberg, B. L., Tran, T. A., Bungay, K. M., Cynn, D. J., \& Rogers, W. H. (1997). Patient based health status measurement in clinical practice: a study of its impact on epilepsy patients' care. Quality of Life Research, 6, 329-341. https://dx.doi.org/10.1023/A:1018479209369.

Wickramasinghe, N., Chalasani, S., Boppana, R.V., \& Madni, A.M. (2007, April). Healthcare system of systems. In System of Systems Engineering, 2007, IEEE International Conference on (1-6). https://dx.doi.org/10.1109/SYSOSE.2007.4304283

Wieland, H., Polese, F., Vargo, S. L., \& Lusch, R. F. (2012). Toward a Service (Eco) Systems Perspective on Value Creation. International Journal of Service Science, Management, Engineering, and Technology (IJSSMET), 3(3), 12-25. https://dx.doi.org/10.4018/jssmet.2012070102

Wieland, H., Vargo, S. L., \& Akaka, M. A. (2016). Zooming out and zooming in: service ecosystems as venues for collaborative innovation. In Service Innovation (35-50). https://dx.doi.org/10.1007/978-4-431-54922-2_2

Wiklund, I. (2004). Review of the quality of life and burden of illness in gastroesophageal reflux disease. Digestive diseases, 22(2), 108-114. https://dx.doi.org/10.1159/000080308

Williams, B. (1994). Patient satisfaction: a valid concept? Social Science \& Medicine, 38(4), 509-516. https://dx.doi.org/10.1016/0277-9536(94)90247-X

Winkel, G., Saegert, S., \& Evans, G. W. (2009). An ecological perspective on theory, methods, and analysis in environmental psychology: Advances and challenges. Journal of Environmental Psychology, 29(3), 318-328. https://dx.doi.org/10.1016/j.jenvp.2009.02.005

Zainuddin, N., Previte, J. \& Russell-Bennett, R. (2011). A social marketing approach to value creation in a well-women's health service. Journal of Marketing Management, 27(3-4), 361-385. https://dx.doi.org/10.1080/0267257X.2011.547081

Zaller, J. R., \& Feldman, S. (1992). A Simple Theory of the Survey Response: Answering Questions versus Revealing Preferences. American Journal of Political Science, 36, 579-616. https://dx.doi.org/10.2307/2111583

Zeithaml, V. A. (1988). Consumer perceptions of price, quality, and value: A means-end model and synthesis of evidence. The Journal of Marketing, 52(3), 2-22. https://dx.doi.org/10.2307/1251446

Zhao, J., Wang, T., \& Fan, X. (2015). Patient value co-creation in online health communities: Social identity effects on customer knowledge contributions and membership continuance intentions in online health communities. Journal of Service Management, 26(1), 72-96. https://dx.doi.org/10.1108/JOSM-12-2013-0344

\section{Copyrights}

Copyright for this article is retained by the author(s), with first publication rights granted to the journal.

This is an open-access article distributed under the terms and conditions of the Creative Commons Attribution license (http://creativecommons.org/licenses/by/4.0/). 